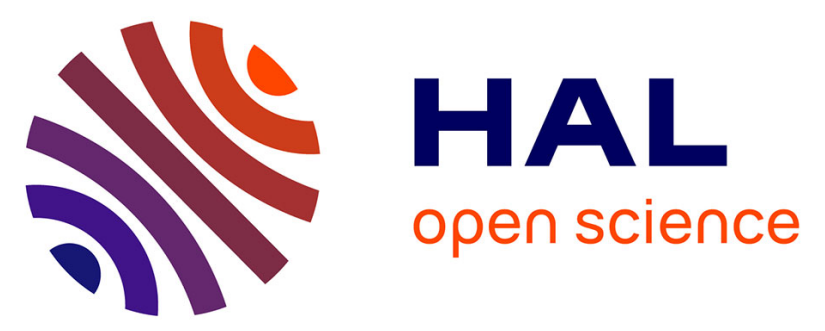

\title{
Sources of Dentin-Pulp Regeneration Signals and Their Modulation by the Local Microenvironment
} Fanny Chmilewsky, Charlotte Jeanneau, Jacques Dejou, Imad About

\section{To cite this version:}

Fanny Chmilewsky, Charlotte Jeanneau, Jacques Dejou, Imad About. Sources of Dentin-Pulp Regeneration Signals and Their Modulation by the Local Microenvironment. Journal of Endodontics, 2014, 40 (4), pp.S19-S25. 10.1016/j.joen.2014.01.012 . hal-03547648

\section{HAL Id: hal-03547648 \\ https://hal.science/hal-03547648}

Submitted on 28 Jan 2022

HAL is a multi-disciplinary open access archive for the deposit and dissemination of scientific research documents, whether they are published or not. The documents may come from teaching and research institutions in France or abroad, or from public or private research centers.
L'archive ouverte pluridisciplinaire HAL, est destinée au dépôt et à la diffusion de documents scientifiques de niveau recherche, publiés ou non, émanant des établissements d'enseignement et de recherche français ou étrangers, des laboratoires publics ou privés. 


\title{
Sources of Dentin-Pulp Regeneration Signals and Their Modulation by the Local Microenvironment
}

\author{
Fanny Chmilewsky, PhD, ${ }^{*}$ Charlotte Jeanneau, PhD, ${ }^{*}$ Jacques Dejou, PhD, ${ }^{*}$ \\ and Imad About, $P b D^{*}$
}

\begin{abstract}
Ahstract
Many aspects of dentin pulp tissue regeneration have been investigated, and it has been shown that dentin pulp has a high regeneration capacity. This seems to be because of the presence of progenitor cells and inductive regeneration signals from different origins. These signals can be liberated after the acidic dissolution of carious dentin as well as from pulp fibroblasts and endothelial cells in cases of traumatic injury. Thus, both carious lesions and pulp cells provide the required mediators for complete dentin-pulp regeneration including reparative dentin secretion, angiogenesis, and innervation. Additionally, all dentin pulp insults including carious "infection," traumatic injuries, application of restorative materials on the injured dentin pulp, and subsequent apoptosis are known activators of the complement system. This activation leads to the production of several biologically active fragments responsible for the vascular modifications and the attraction of immune cells to the inflammatory/injury site. Among these, $\mathrm{C} 5 \mathrm{a}$ is involved in the recruitment of pulp progenitor cells, which express the C5a receptor. Thus, in addition to dentin and pulp cells, plasma should be considered as an additional source of regeneration signals. (J Endod 2014;40:S19-S25)
\end{abstract}

\section{Key Words}

Complement, odontoblast, progenitor cells, pulp-dentin regeneration
Tissu acti ssue regeneration strategies require 3 major elements: stem cells, scaffolds, and activation signals. Although many studies were performed to develop a "suitable" scaffold for each particular tissue, numerous investigations were devoted to better understand the stem cells' properties and potential in tissue regeneration both in vitro and in vivo $(1,2)$. However, the signals that orchestrate the regeneration processes were not given much attention. Indeed, stem cells are resting cells residing beside differentiated cells within an intact and functional tissue. With few exceptions, the regenerative function of these cells is induced only after tissue injury in cases of trauma or under pathological conditions. Stem cell induction appears as the result of activation signals originating from the modified microenvironment. This pinpoints the fact that understanding what happens in case of pathology/injury is essential in understanding the role of activation signals in the regeneration processes (3).

This is of prime importance in cases of dentin-pulp regeneration, which occurs under carious or traumatic injuries. These events lead to an inflammatory reaction, which is believed to be the initial step of tissue regeneration. Within the tooth, dentin-pulp regeneration can take multiple forms depending on the causative agent and the severity of the tissue alteration. This varies from a "simple" up-regulation of the underlying odontoblast synthetic activity, which leads to regenerating a protective reactionary dentin, to more severe dentin-pulp injuries. These usually imply complete pulp dentin regeneration including not only reparative dentin synthesis but also angiogenesis and innervation. This regeneration seems to be dependent not only on the interaction of the dentin with the pulp but also on the interaction between different pulp cell types (4) and between the progenitor cells and other components of the immune/inflammatory response such as the complement biologically active C5a fragment (5). Thus, dentin-pulp regeneration in case of pulp injury requires the activation and proliferation of progenitor cells as well as their migration and differentiation at the injury site. All these processes are orchestrated by signaling molecules. In this review, we discuss the origin of the regeneration signals under normal and pathological conditions and their modulation by inflammation and restorative procedures.

\section{Pulp Progenitor Gell Differentiation In Vitro Is Dependent on the Gulture Conditions}

It has long been established that dental pulp contains progenitor cells capable of dentin regeneration (6). Although other localizations and niches cannot be excluded, 3 independent investigations using 3 different approaches have clearly identified a specific origin of these cells in the perivascular area $(1,7,8)$. When isolated with specific surface markers such as $\mathrm{CD} 34$ /vascular endothelial growth factor receptor 2 (VEGFR2), these cells can undergo adipogenic, chondrogenic, neuronal, and odontoblastic differentiation depending on the culture conditions $(1,6)$. Additionally, these progenitor cells are heterogenous and comprise a subpopulation of $\mathrm{CD} 31^{-} / \mathrm{CD} 146^{-}$, which can undergo endothelial differentiation when cultured with a medium containing basic fibroblast growth factor 2 (FGF-2) and vascular endothelial growth factor (VEGF). This has been shown by the formation of tubular structures on Matrigel (San Jose, CA) and the expression of many endothelial cell markers (1). Taken together, these data clearly indicate that modifying the culture conditions/local environment affects the cell fate/differentiation potential. 


\section{The Transplantation Site Affects the Pulp Progenitor's Fate}

Similar results indicate that the microenvironment also controls the fate of progenitor cells in vivo. This effect is nicely shown through transplantation experiments. When STR0-1-positive pulp progenitor cells were mixed with hydroxyapatite/tricalcium phosphate ceramic powder followed by transplantation into immunocompromised mice, dentinpulp-like tissue was generated (9). Similarly, when they were transplanted on dentin slices, pulp cells generated tubular reparative dentin on the slice surface (10). Surprisingly, when progenitor cells from exfoliated teeth were transplanted with hydroxyapatite in vivo, bone regeneration was obtained (11). This was also best shown in autotransplantation experiments in which progenitor cell transplantation with $\beta$-tricalcium phosphate into swine mandibular critical bone defects led to bone regeneration (2). Interestingly, when pulp progenitor cells that express CD34 and VEGFR2 but not CD31 or CD146 were injected into an ischemic site of a mouse hind limb, they led to re-establishment of blood flow and vascularization (1). On the other hand, when the same cells were labeled with fluorescent Dil-acetylated-LDL (Biomedical Technologies Inc, Schiltigheim, France) dye and autotransplanted into amputated pulp of dog teeth in a scaffold of collagen type I and type III, the DiI-labeled cells were observed in the amputated area closely related to newly formed capillaries and expressed several proangiogenic factors implying trophic action on endothelial cells (12). Similarly, when stem cells from exfoliated deciduous teeth were seeded onto tooth slice/scaffolds and implanted subcutaneously into immunodeficient mice, they differentiated into functional odontoblasts and endothelial cells only after the addition of VEGF (13).

These data show clearly that pulp progenitors differentiate into odontoblastic cells when transplanted into the pulp and into other cell types in vitro or when transplanted into other sites in vivo. This indicates that the regeneration signals affecting progenitor cell differentiation originate from the local environment.

\section{Injuries and Restorative Materials Modify the Dentin-Pulp Microenvironment}

Dentin pulp is subject to injuries with various degrees of severity. These can be caused by carious or traumatic injuries and the subsequent application of a restorative material. All these injuries are responsible for dentin-pulp modifications. Indeed, dentin bioactive molecules such as growth factors can be solubilized and liberated from the dentin by acids that can be produced during the carious injury progression because of bacterial metabolism. These factors can also be released from the dentin during the total-etching restorative procedures in which dentin etching does not only remove the smear layer and smear plugs but also results in a superficial demineralization of the underlying dentin (14). Thus, during dentin demineralization that occurs after carious irritation, these signaling molecules can be released from the dentin matrix and diffuse to reach the pulp cells. The secretory activity of the odontoblasts is then stimulated, leading to the production of a reactionary dentin (15-17). This effect has also been shown by the fact that both calcium hydroxide and mineral trioxide aggregate can solubilize transforming growth factor beta 1 (TGF- $\beta 1$ ) from the dentin $(18,19)$. Similarly, both materials together with Biodentine (Septodont, Saint-Maur-desFossés, France) have been shown to induce the secretion of significant quantities of TGF- $\beta 1$ from cultured human pulp fibroblasts (20). Given the well-established role of this growth factor in progenitor cell recruitment and odontoblast differentiation, this explains, at least in part, the therapeutic success of these materials in direct pulp capping or in deep cavities. Opposed to these bioactive materials, a decrease in TGF$\beta 1$ secretion was observed after applying the Xeno III self-etching adhe- sive (Dentsply DeTrey GmbH, Konstanz, Germany). Additionally, it has been reported that resinous monomers reduce the secretion of other growth factors from pulp cells such as FGF-2 and appear to be responsible for the intracellular accumulation of dentin sialoprotein and osteonectin within the endoplasmic reticulum (21). These proteins are involved in extracellular matrix mineralization and need to be secreted to accomplish their function. This accumulation explains why after pulp cells were incubated even with nontoxic concentrations of resinous monomers the mineralization was inhibited (22).

\section{Dentin Acts as a Reservoir of Regeneration Signals}

Many growth factors are assumed to play a role in pulp-dentin regeneration $(23,24)$. Among these factors, VEGF, platelet-derived growth factors, FGF-2, and TGF- $\beta 1$ are secreted and sequestered in the dentin $(25,26)$. These factors can be liberated by the acidic environment at the carious site and diffuse via the dentin tubules to stimulate the underlying odontoblasts to secrete a reactionary dentin locally. Among these factors, TGF- $\beta 1$, TGF- $\beta 3$, and bone morphogenetic protein 7 have been shown to up-regulate odontoblast secretory activity $(25,27)$.

On the other hand, the odontoblasts that border the dental pulp act as sensors of external stimuli. These cells have cytoplasmic processes throughout the dentin and lie in close proximity to sensory unmyelinated nerve fibers, which extend from the dental pulp to the inner half of the dentin (28). Emerging evidence supports a role for odontoblasts as sensory cells that may sense external stimuli and transduce the signal to nearby neural cells, which is supported by the close apposition of the odontoblasts to the dentinal nerve terminals (29). Recent data have shown that these cells express transient receptor potential (TRP) ion channels (30). These channels are known for their capacity to directly mediate nociceptive functions because of thermal and chemical stimuli. Odontoblasts express transient receptor potential vanilloide 1 that responds to noxious heat and transient receptor potential cation channel melastin 8 and ankyrin A1 that mediate cool and noxious cold sensations, respectively. In addition, these receptors are sensitive to chemical stimulation (30). Thus, although the dentin pulp is the main target of bacteria/toxins and restorative materials, odontoblasts deposit a protective reactionary dentin because they act as sensor cells that are responsive to dentin-solubilized regeneration signals.

\section{Pulp Cells Secrete Regeneration Signals after Pulp Injury}

Severe caries lesions or deep cavity preparations may lead to odontoblast destruction. However, a new generation of odontoblastlike cells is responsible for reparative dentin apposition within the pulp chamber (31). This results in tubular dentin secretion discontinuous from the physiological dentin in terms of tubular structure. The reparative dentin secretion is a complex process requiring the presence of responsive progenitor cells as well as the appropriate signals for their activation and differentiation. Again, growth factors liberated under caries lesions play a role in reparative dentin secretion; TGF- $\beta 1$, FGF2 , and BMP-2 and -4 seem to be involved in the proliferation and differentiation of pulp cells $(32,33)$.

However, after surgical pulp amputation, healing can occur with hard tissue formation in germ-free animals independent of growth factor release from the dentin $(34,35)$. This is suggestive of the autoreparative pulp potential after traumatic injuries.

Indeed, investigating pulp fibroblasts' and endothelial cells' secretory activity revealed some interesting aspects related to their functions both under normal and pathological conditions. It has been shown that 
pulp fibroblasts isolated from human third molars secrete FGF-2, VEGF, and platelet-derived growth factors in vitro. When these cells were stimulated by a traumatic injury, their secretion of growth factors significantly increased, and this increase was observed 6 hours after the injury (36). The same results were obtained with endothelial cells, which secrete both VEGF and FGF without any stimulation (4). However, after a physical injury to the endothelial cell layer, a significant increase of the growth factors was observed within hours of injury. Interestingly, this reveals that the injury itself induced a modification of the microenvironment via the secretion of growth factors. In an attempt to understand the consequences of this secretion on pulp regeneration processes, a coculture system allowed the investigation of the consequences of a physical injury on neoangiogenesis in vitro. After performing physical injuries to pulp fibroblasts, the culture medium containing the soluble factors was collected and was applied onto endothelial cell cultures. Surprisingly, endothelial cells started to organize into closed "tubular" structures corresponding to neoangiogenesis in vitro
(37). In addition to FGF-2 effects on angiogenesis, this factor may act as a mitogen for pulp progenitor cells. It stimulates the proliferation of rat immature dental pulp cells and has an inductive activity on mineralized calcium production in 3-dimensional cultures of dental pulp cells in collagen type I gel. Exogenous TGF- $\beta$ s, FGFs, and bone morphogenetic proteins have shown their potential in signaling reparative dentinogenesis. Their involvement was investigated after direct application onto the pulp by evaluating pulp-dentin regeneration $(24,25,38$, 39). Moreover, pulp cells from both rats and humans express messenger RNAs and release the corresponding neurotrophic proteins. Although the production of neurotrophic factors by dental pulp cells plays an important role in tooth innervation during development, continued production by mature pulp cells is involved in nerve growth and guidance (40). This has been shown by the fact that explants of young rat trigeminal ganglia extend neurites when cocultivated with pulpal tissue explants, suggesting that pulpal cells stimulate the growth of trigeminal ganglia axons with soluble molecules
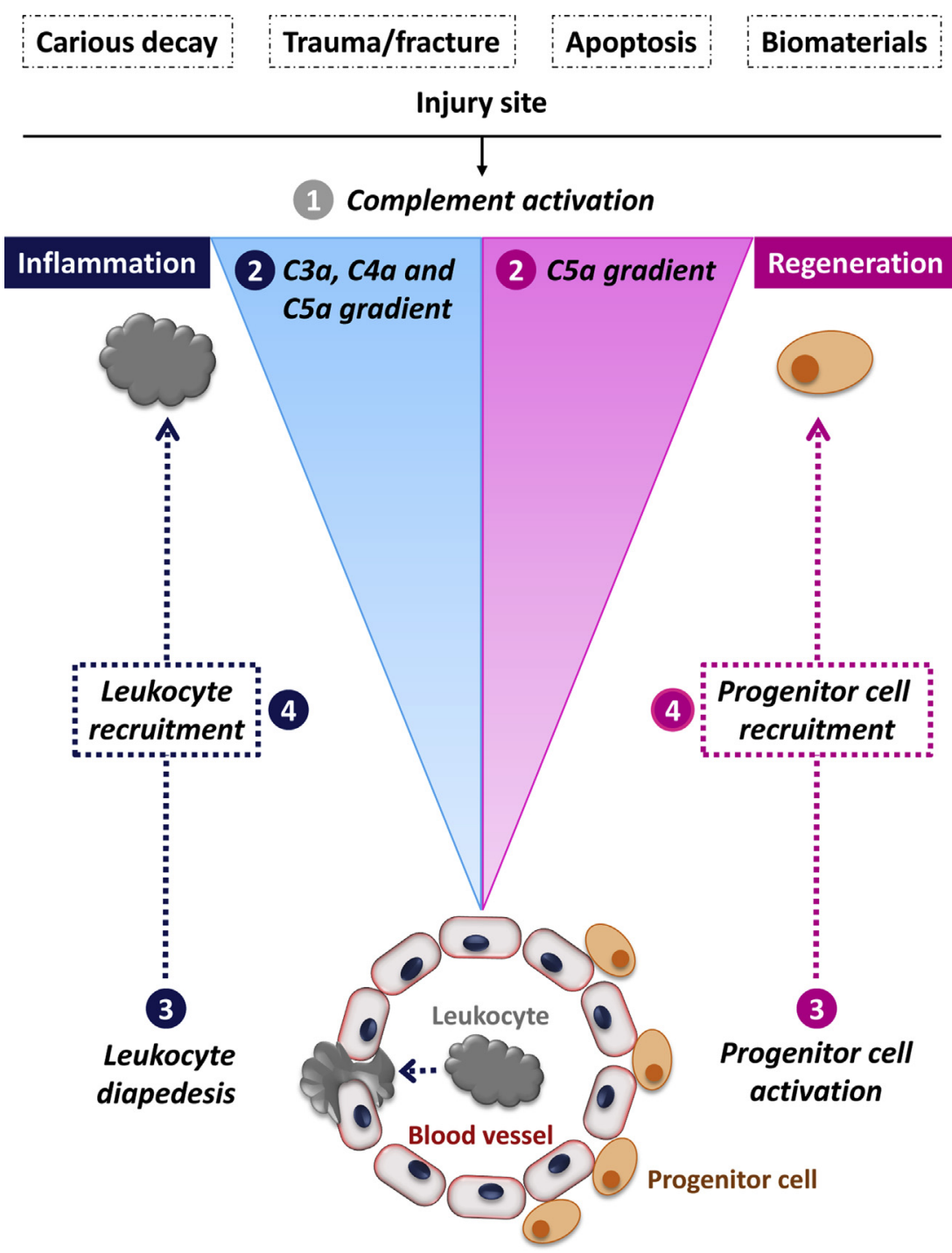

Figure 1. Complement activation initiates inflammation and regeneration simultaneously in dentin pulp. Carious decay, traumatic injuries, apoptosis, and biomaterial application lead to complement activation at the tissue injury site. The soluble fragments C3a, C4a, and C5a produced after complement activation modify the vascular permeability indirectly by inducing basophiles/mastocytes degranulation. This leads to a massive liberation of histamine and serotonin, which increases vascular permeability. They also act on endothelial cell permeability by inducing fiber stress formation, which facilitates leukocyte diapedesis upon contraction. The created gradient of these fragments guides leukocyte migration toward the infected/inflamed tissue. In parallel, C5a activates pulp progenitor cells, and the produced $\mathrm{C} 5$ a gradient guides their migration toward the injured tissue to initiate the dentin-pulp regeneration process. 


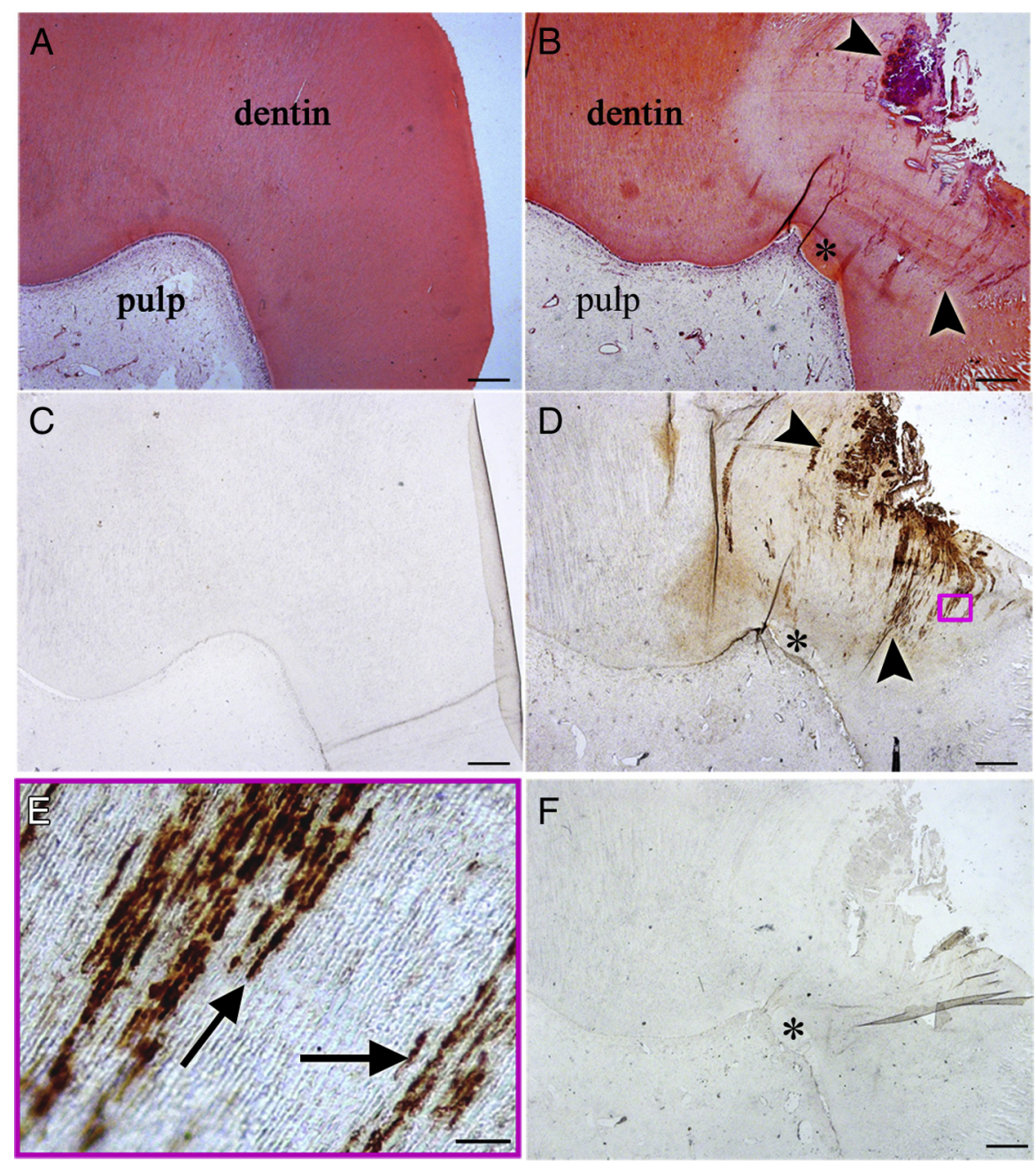

Figure 2. Complement activation in vivo. Immunohistochemistry was used to investigate complement activation through the formation of the cytolytic membrane attack complex (C5b-9) in $(A$ and $C)$ intact and $(B$ and $D-F)$ carious teeth. $(C)$ Although $C 5 \mathrm{~b}-9$ complex was not detected in noncarious dentin of the intact tooth, $(D)$ its labeling was intense in the carious tooth, and $(E)$ the labeling correlated to the bacterial location within the dentin tubules. $(F)$ No labeling was observed in the controls. $(A$ and $B)$ Hematoxylin-eosin stain. Arrowheads indicate caries lesions, arrows indicate $\mathrm{C} 5 \mathrm{~b}-9$ binding of bacteria in dentin tubules, and the asterisk indicates reparative dentin. Scale bars: $A-D$ and $F=500 \mu \mathrm{m}, E=20 \mu \mathrm{m}$.

(41). This clearly shows that any local tissue modification has direct consequences on dentin-pulp regeneration.

\section{Complement Activation Produces Essential Molecules Initiating Inflammation}

The coagulation and complement systems are efficient plasma cascades that play essential roles in inflammation and immune defense mechanisms. The complement system is a major component of the immune system, consisting of a proteolytic cascade of more than 30 plasma and cellular proteins (42). It is activated via 3 principle pathways:

1. The classic pathway is mainly activated by the formation of antigenantibody complexes but can also be activated by biomaterials (43), apoptotic/necrotic cells, and pathogen-associated molecular patterns.

2. The lectin pathway is known to be activated directly by pathogen surface and especially by carbohydrates and other pathogen-associated molecular patterns.

3. The alternative pathway is constitutively activated by spontaneous hydrolysis but may be triggered directly by foreign surfaces like microorganisms or man-made biomaterials (44).
The complement system activation by either pathway leads to the production of 3 kinds of effectors that allow the complement system to fulfill 3 essential roles regarding immune defense mechanisms. First, $\mathrm{C} 3 \mathrm{~b}$ and $\mathrm{C} 5 \mathrm{~b}$ opsonins coat the pathogen surface to enhance its clearance by the phagocytic system. Second, the membrane attack complex (C5b-9) fixation into the lipid membrane of cells and pathogens leads to transmembrane pore formation and cell lysis. Finally, the anaphylatoxins ( $\mathrm{C} 3 \mathrm{a}, \mathrm{C} 4 \mathrm{a}$, and especially $\mathrm{C} 5 \mathrm{a}$ ) are important mediators of inflammation inducing the vascular permeability by stimulating histamine and serotonin release from mastocytes and basophils and fiber stress formation in endothelial cells. Moreover, these anaphylatoxins are powerful chemotactic factors of leukocyte recruitment to the complement activation site (Fig. 1).

\section{Complement Activation Is Also Involved in the Regeneration Process}

Tissue regeneration and inflammation are tightly linked processes, and tissue regeneration is completely dependent on the inflammatory reaction. This has been clearly shown in the context of myocardial infarction in which the corticoids used to decrease inflammation significantly reduced the tissue regeneration process (45). The complement 

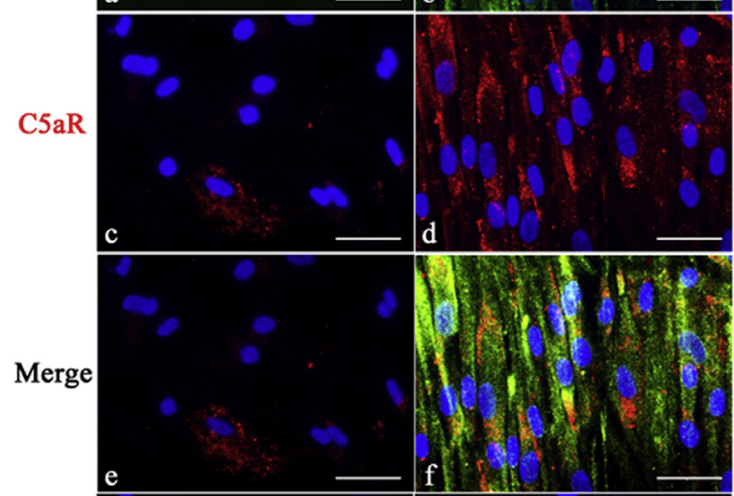

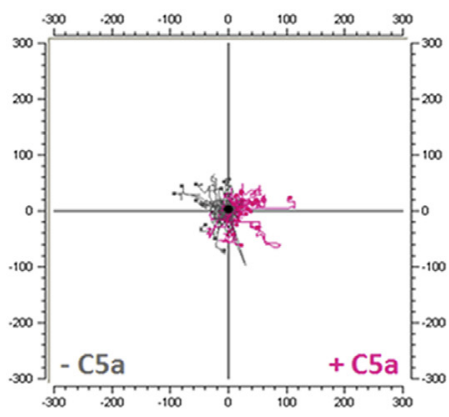

b Unsorted cells

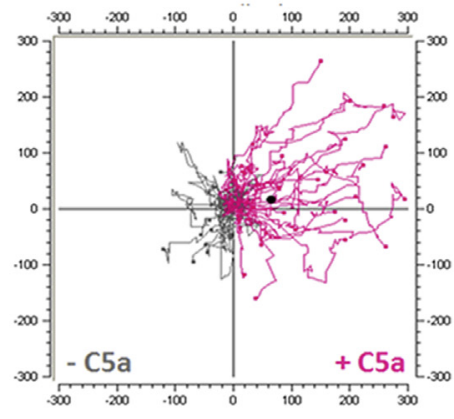

C STRO-1 sorted cells

Control

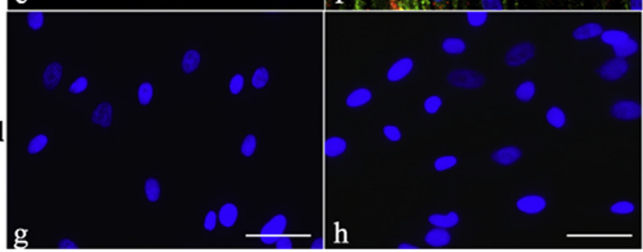

(1)

Figure 3. (A) The expression of C5aR by pulp progenitor STRO-1-sorted cells. (a) Although STRO-1 was not expressed by unsorted cells, (b) this surface marker was expressed by all STRO-1-sorted cells. Similarly, (c) although only a few unsorted cells showed the expression of C5aR, (d) all STRO-1-sorted cells appeared to express C5aR. (e) Merged images of STR0-1 and C5aR revealed that some unsorted cells expressed C5aR, (f) whereas STR0-1-sorted cells coexpressed both STR0-1 and C5aR. No immunostaining was observed with the (g) negative unsorted or (h) on STRO-1-sorted cells. Scale bars $=50 \mu \mathrm{m}$. $(B)$ C5a induces selective pulp progenitor STR0-1-sorted cell migration. (a) A schematic representation of the migration system used ( $\mu$-slide chemotaxis 3-dimensional chamber crosssection). Pulp cells were seeded into a C5a gradient and followed for 48 hours. (b and c) Representative plots of cell migration over a 48-hour period: (b) unsorted cells' trajectory plots and (c) STR0-1-sorted cells' trajectory plots. (b) No directed migration can be measured for unsorted cells, (c) whereas STRO-1-sorted cells migrate toward the $\mathrm{C} 5$ a gradient.

is known to play a major role in initiating and amplifying the inflammatory reaction. This role is mainly mediated by the $\mathrm{C} 3 \mathrm{a}$ and $\mathrm{C} 5 \mathrm{a}$ anaphylatoxins. Although the importance of C3a still raises some debates (46), that of $\mathrm{C} 5 \mathrm{a}$ is well established. Indeed, $\mathrm{C} 5 \mathrm{a}$ has a powerful chemotactic effect on C5aR-expressing cells. Basically, this receptor is mainly expressed by immune cells such as neutrophils, eosinophils, basophils/ mastocytes, monocytes/macrophages, dendritic cells, and B and T lymphocytes $(47,48)$. However, in addition to various immune cells, several nonimmune cells express C5aR including endothelial cells; astrocytes, cells from skin, intestine, and heart; and human mesenchymal stem cells (49). This receptor is also expressed by cells involved in the mineralization process, such as osteoblasts (50). In addition, it has been shown that some stem/progenitor cells express this receptor (51).

\section{C5a and Tissue Regeneration}

Several investigations showed the involvement of $\mathrm{C} 5 \mathrm{a}$ in tissue regeneration. This has been studied in the liver, which has a very high regeneration capacity (51). Indeed, when C5-deficient mice were subjected to a toxic damage after CCL 4 chemokine treatment, their liver could not regenerate. However, liver regeneration was observed after injecting $\mathrm{C} 5$ or $\mathrm{C} 5 \mathrm{a}$ to the treated animals (52). This role has also been shown in cardiac tissue regeneration in which C5a not only induced the migration of progenitor cells but also their differentiation (53). After human bone fracture, a significant increase of C5aR expres- sion was observed in mesenchymal progenitors during osteogenic differentiation. This study also showed that $\mathrm{C5a}$ induces the migration of mesenchymal progenitor cells as well as osteoblasts showing C5a involvement in fractured bone regeneration (54).

\section{Dental Pulp Is Subject to Various Insults Leading to Complement Activation}

Dental pulp is subject to various types of injuries, which lead to an inflammatory reaction. These include carious decay, traumatic injuries/ fractures, and the therapeutic application of a restorative material. It has been shown that biomaterials that contain free $\mathrm{OH}, \mathrm{NH} 3$, or carboxylic acid groups are involved in the complement activation $(55,56)$. It has also been reported that $\mathrm{Ni}(2+)$ and $\mathrm{Co}(2+)$ induce complement activation in plasma samples as shown by the cleavage of complement factor $\mathrm{C} 3$ to $\mathrm{C} 3 \mathrm{~b}$ (55). Additionally, during the management of pulp lesions, odontoblast and pulp cells may undergo apoptosis (56). All these events are well-established complement activation mechanisms (Fig. 1).

\section{Complement Activation and Dentin-Pulp Regeneration}

It has been shown that carious injuries, like any bacterial infection, activate complement as revealed by the cytolytic membrane attack complex (C5b-9) formation in human third molars (5). This complex binds onto the bacterial membrane as shown in the 
TABLE 1. Sources of Dentin-Pulp Regeneration Signals

\begin{tabular}{|c|c|c|c|}
\hline Sources & Insults & Mediators & Effects \\
\hline $\begin{array}{l}\text { Dentin/odontoblast } \\
\qquad(14-18,23,24,37-39)\end{array}$ & Carious & FGF-2, VEGF, PDGF, TGF- $\beta 1 \ldots$ & $\begin{array}{l}\text { Progenitor and pulp cell proliferation, } \\
\text { angiogenesis, directing progenitor }\end{array}$ \\
\hline Pulp fibroblasts $(27,31,32)$ & Carious, trauma/biomaterial & FGF-2, VEGF, PDGF, TGF- $\beta 1$ & $\begin{array}{l}\text { cell migration, odontoblastic } \\
\text { differentiation }\end{array}$ \\
\hline Endothelial cells (4) & Carious, trauma & FGF-2, VEGF, & Pulp cell proliferation, angiogenesis \\
\hline Plasma (5) & Carious, trauma & $\mathrm{C} 5 \mathrm{a}$ & Directing progenitor cell migration \\
\hline
\end{tabular}

FGF-2, basic fibroblast growth factor 2 ; PDGF, platelet-derived growth factor; TGF- $\beta 1$, transforming growth factor beta 1 ; VEGF, vascular endothelial growth factor.

tubules of decayed dentin and pulp (Fig. $2 A-F$ ). This activation implies the generation of biologically active fragments including a $\mathrm{C} 5 \mathrm{a}$ gradient production. In an attempt to understand the potential role of this fragment in dentin-pulp regeneration, a cell migration design was used to study the interactions between pulp progenitor cells and the $\mathrm{C} 5$ a fragment (5).

Using the magnetic cell sorting approach of human pulp progenitor cells with the mesenchymal STRO-1 stem cell marker, it has been shown that the isolated pulp progenitors also express C5aR as shown by immunofluorescence double staining (Fig. $3 A$ ). This has also been shown in human teeth in which both STR0-1 and C5aR were coexpressed by the same cells in the perivascular area, which corresponds to the perivascular niche of pulp progenitor cells (5). When STR0-1sorted progenitor cells expressing $\mathrm{C} 5 \mathrm{aR}$ were subjected to a $\mathrm{C} 5 \mathrm{a}$ gradient in a migration chamber, they migrated toward a $\mathrm{C} 5 \mathrm{a}$ gradient, whereas the nonsorted cells exhibited random movements (Fig. $3 B$ ). The interaction specificity between C5a and STRO-1-sorted progenitor cells has been shown by adding the C5aR antagonist W54011, which significantly inhibited the binding (5).

Thus, after complement activation, a C5a gradient is produced, and this gradient guides the pulp progenitor cells to the complement activation site/inflammatory site (Fig. 1). This clearly shows the involvement of $\mathrm{C} 5 \mathrm{a}$ in 1 of the early and essential steps of dentin-pulp regeneration. Indeed, after odontoblast disintegration in deep/severe carious/traumatic injuries, a migration of progenitor cells is required to replace the missing odontoblasts and to secrete a protective reparative dentin. Although the $\mathrm{C} 5$ a fragment is produced within minutes of complement activation and provides a very quick signal for initiating the inflammatory reaction, it is also involved in the regeneration process via the recruitment of pulp progenitor cells.

These findings do not exclude the involvement of other mechanisms during this critical step. Indeed, dentin and pulp matrix components (57), liposaccharides (58), and stromal cell-derived factor 1 (SDF-1) (59) have been shown to contribute to pulp cell migration. Interestingly, among the cells expressing SDF-1 receptor, a high percentage was STR0-1 positive and had progenitor cell properties such as colony formation, high proliferation rate, a multilineage differentiation potential, and expressed chemokine receptor 4 (CXCR4) $(60,61)$. Also, it is well established that CXCR4-expressing cells are responsive to SDF-1, which can attract CXCR4-positive cells from their niches in response to stimulations related to tissue damage or infection (60). In line with this, it has been shown that SDF-1 and CXCR4 messenger RNA expression increases in inflamed dental pulps (59).

These data contribute to a better understanding of the mechanisms involved in progenitor cell migration to the infectious/injury site in order to regenerate the damaged dentin. Thus, in addition to the signals produced from the dentin, pulp fibroblasts, and endothelial cells, complement activation and its consequences to pulp regeneration clearly show that the plasma should be considered as an important additional source providing $\mathrm{C} 5 \mathrm{a}$ as a new signal involved in dentin-pulp regeneration.

\section{Conclusions}

Regeneration signals of the dentin pulp have different sources (Table 1). The soluble extracellular matrix molecules of dentin, pulp fibroblasts, and endothelial cells are involved in complete dentinpulp regeneration. This review adds to our understanding that complement activation is involved in the regeneration process by inducing progenitor cell recruitment. This regeneration process is rather complex implying many signals and starts very quickly during the inflammatory reaction after any dentin-pulp damage.

\section{Acknowledgments}

Supported by funding from Aix-Marseille University and CNRS. The authors deny any conflicts of interest related to this study.

\section{References}

1. Iohara K, Zheng L, Wake H, et al. A novel stem cell source for vasculogenesis in ischemia: subfraction of side population cells from dental pulp. Stem Cells 2008; 26:2408-18.

2. Zheng Y, Liu Y, Zhang CM, et al. Stem cells from deciduous tooth repair mandibular defect in swine. J Dent Res 2009;88:249-54.

3. About I. Dentin-pulp regeneration: the primordial role of the microenvironment and its modification by traumatic injuries and bioactive materials. Endod Top 2013;28:61-89.

4. About I. Dentin regeneration in vitro: the pivotal role of supportive cells. Adv Dent Res 2011;23:320-4.

5. Chmilewsky F, Jeanneau C, Laurent $P$, et al. Pulp progenitor cell recruitment is selectively guided by a C5a gradient. J Dent Res 2013;92:532-9.

6. About I, Bottero MJ, De Denato P, et al. Human dentin production in vitro. Exp Cell Res 2000;258:33-41.

7. Shi S, Gronthos S. Perivascular niche of postnatal mesenchymal stem cells in human bone marrow and dental pulp. J Bone Miner Res 2003;18:696-704.

8. Téclès 0 , Laurent $P$, Zygouritsas $S$, et al. Activation of human dental pulp progenitor/ stem cells in response to odontoblast injury. Arch Oral Biol 2005;50:103-8.

9. Gronthos S, Brahim J, Li W, et al. Stem cell properties of human dental pulp stem cells. J Dent Res 2002;81:531-5.

10. Batouli S, Miura M, Brahim J, et al. Comparison of stem-cell-mediated osteogenesis and dentinogenesis. J Dent Res 2003;82:976-81.

11. Miura M, Gronthos S, Zhao M, et al. SHED: stem cells from human exfoliated deciduous teeth. Proc Natl Acad Sci U S A 2003;100:5807-12.

12. Iohara K, Zheng L, Ito M, et al. Regeneration of dental pulp after pulpotomy by transplantation of CD31(-)/CD146(-) side population cells from a canine tooth. Regen Med 2009;4:377-85.

13. Sakai VT, Zhang Z, Dong Z, et al. SHED differentiate into functional odontoblasts and endothelium. J Dent Res 2010;89:791-6.

14. Van Meerbeek B, Inokoshi S, Braem M, et al. Morphological aspect of the resindentin interdiffusion zone with different dentin adhesive systems. J Dent Res $1992 ; 71: 1530-40$.

15. About I, Laurent-Maquin D, Lendahl U, et al. Nestin expression in embryonic and adult human teeth under normal and pathological conditions. Am J Pathol 2000; 157:287-95.

16. Goldberg M, Smith AJ. Cells and extracellular matrices of dentin and pulp: a biological basis for repair and tissue engineering. Crit Rev Oral Biol Med 2004;15:13-27.

17. Tziafas D, Smith AJ, Lesot H. Designing new treatment strategies in vital pulp therapy. J Dent 2000;28:77-92.

18. Graham L, Cooper PR, Cassidy N, et al. The effect of calcium hydroxide on solubilisation of bio-active dentine matrix components. Biomaterials 2006;27:2865-73. 
19. Tomson PL, Grover LM, Lumley PJ, et al. Dissolution of bio-active dentine matrix components by mineral trioxide aggregate. J Dent 2007;35:636-42.

20. Laurent P, Camps J, About I. Biodentine induces TGF-b1 release from human pulp cells and early dental pulp mineralization. Int Endod J 2012;45:439-48.

21. Diamanti E, Mathieu S, Jeanneau C, et al. Endoplasmic reticulum stress and mineralization inhibition mechanism by the resinous monomer HEMA. Int Endod J 2013; 46:160-8.

22. About I, Camps J, Mitsiadis TA, et al. Influence of resinous monomers on the differentiation in vitro of human pulp cells into odontoblasts. J Biomed Mater Res 2002 ; 63:418-23.

23. Iohara K, Nakashima M, Ito M, et al. Dentin regeneration by dental pulp stem cell therapy with recombinant human bone morphogenetic protein 2. J Dent Res 2004; $83: 590-5$.

24. Unda FJ, Martin A, Hernandez C, et al. FGFs-1 and -2, and TGF beta 1 as inductive signals modulating in vitro odontoblast differentiation. Adv Dent Res 2001;15:34-7.

25. Sloan AJ, Smith AJ. Stimulation of the dentine-pulp complex of rat incisor teeth by transforming growth factor-beta isoforms 1-3 in vitro. Arch Oral Biol 1999; 44 : $149-56$.

26. Goldberg M, Lacerda-Pinheiro S, Jegat N, et al. The impact of bioactive molecules to stimulate tooth repair and regeneration as part of restorative dentistry. Dent Clin North Am 2006;50:277-98.

27. Sloan AJ, Rutherford RB, Smith AJ. Stimulation of the rat dentine-pulp complex by bone morphogenetic protein-7 in vitro. Arch Oral Biol 2000;45:173-7.

28. Byers MR, Närhi MV. Dental injury models: experimental tools for understanding neuroinflammatory interactions and polymodal nociceptor functions. Crit Rev Oral Biol Med 1999;10:4-39.

29. Maurin JC, Couble ML, Didier-Bazes M, et al. Expression and localization of reelin in human odontoblasts. Matrix Biol 2004;23:277-85.

30. El Karim IA, Linden GJ, Curtis TM, et al. Human odontoblasts express functional thermo-sensitive TRP channels: implications for dentin sensitivity. Pain 2011;152: 2211-23.

31. Fitzgerald M, Chiego DJ, Heys DR. Autoradiographic analysis of odontoblast replacement following pulp exposure in primate teeth. Arch Oral Biol 1990;35:707-15.

32. Martin P. Wound healing. Aiming for perfect skin regeneration. Science 1997;276 75-81.

33. Shiba H, Nakamura S, Shirakawa M, et al. Effects of basic fibroblast growth factor on proliferation, the expression of osteonectin (SPARC) and alkaline phosphatase, and calcification in cultures of human pulp cells. Dev Biol 1995;170:457-66.

34. Inoue T, Shimono M. Repair dentinogenesis following transplantation into normal and germ-free animals. Proc Finn Dent Soc 1992;88:183-94.

35. Tsuji T, Takel K, Inoue T, et al. An experimental study on wound healing of surgical exposed dental pulps in germ-free rats. Bull Tokyo Dent Coll 1987;28:35-8.

36. Tran-Hung L, Laurent P, Camps J, et al. Quantification of angiogenic growth factors released by human dental cells after injury. Arch Oral Biol 2008;52:9-13.

37. Tran-Hung L, Mathieu S, About I. Role of human pulp fibroblasts in angiogenesis J Dent Res 2006;85:819-23.

38. Mathieu S, Jeanneau C, Sheibat-Othman N, et al. Usefulness of controlled release of growth factors in investigating the early events of dentin-pulp regeneration. J Endod 2013;39:228-35.

39. Nakashima M. Induction of dentin in amputated pulp of dogs by recombinant human bone morphogenetic proteins- 2 and -4 with collagen matrix. Arch Oral Biol 1994:39:1085-9.

40. Nosrat IV, Smith CA, Mullally P, et al. Dental pulp cells provide neurotrophic support for dopaminergic neurons and differentiate into neurons in vitro; implications for tissue engineering and repair in the nervous system. Eur J Neurosci 2004;19: 2388-98.

41. Lillesaar C, Eriksson C, Johansson CS, et al. Tooth pulp tissue promotes neurite outgrowth from rat trigeminal ganglia in vitro. J Neurocytol 1999;28:663-70.

42. Ricklin D, Hajishengallis G, Yang K, et al. Complement-a key system for immune surveillance and homeostasis. Nat Immunol 2010;11:785-97.

43. Tengvall P, Askendal A, Lundström II. Ellipsometric in vitro studies on the activation of complement by human immunoglobulins $\mathrm{M}$ and $\mathrm{G}$ after adsorption to methylated silicon. Colloids Surf B Biointerfaces 2001;20:51-62.

44. Andersson J, Ekdahl KN, Larsson R, et al. C3 adsorbed to a polymer surface can form an initiating alternative pathway convertase. J Immunol 2002;168:5786-91.

45. Kloner RA, Fishbein MC, Lew H, et al. Mummification of the infarcted myocardium by high dose corticosteroids. Circulation 1978;57:56-63.

46. Busche MN, Stahl GL. Role of the complement components C5 and C3a in a mouse model of myocardial ischemia and reperfusion injury. GMS 2010;8:1612-3174.

47. Morelli A, Larregina A, Chuluyan E, et al. Expression and modulation of C5a receptor (CD88) on skin dendritic cells. Chemotactic effect of C5a on skin migratory dendritic cells. Immunology 1996;89:126-34.

48. Werfel T, Oppermann M, Bergemann G, et al. C5a receptors are detectable on mast cells in normal human skin and in psoriatic plaques but not in weal and flare reactions or in uticaria pigmentosa by immunohistochemistry. Arch Dermatol Res 1997;289:83-6.

49. Schraufstatter I, DiScipio RG, Zhao M, et al. C3a and C5a are chemotactic factors for human mesenchymal stem cells which cause prolonged ERK1/2 phosphorylation. J Immunol 2009;182:3827-36.

50. Ignatius A, Schoengraf P, Kreja L, et al. Complement C3a and C5a modulate osteoclast formation and inflammatory response of osteoblasts in synergism with IL-1 $\beta$. J Cell Biochem 2011;112:2594-605.

51. Michalopoulos GK, DeFrances MC. Liver regeneration. Science 1997;276:60-6.

52. Mastellos D, Papadimitriou JC, Franchini S, et al. A novel role of complement: mice deficient in the fifth component of complement (C5) exhibit impaired liver regeneration. J Immunol 2001;166:2479-86.

53. Lara-Astiaso D, Izarra A, Estrada JC, et al. Complement anaphylatoxins C3a and C5a induce a failing regenerative program in cardiac resident cells. Evidence of a role for cardiac resident stem cells other than cardiomyocyte renewal. Springerplus 2012;1: 63-78.

54. Ignatius A, Ehrnthaller C, Brenner RE, et al. The anaphylatoxin receptor C5aR is present during fracture healing in rats and mediates osteoblast migration in vitro. Trauma 2011;71:952-60.

55. Acevedo F, Vesterberg 0 . Nickel and cobalt activate complement factor C3 faster than magnesium. Toxicology 2003;185:9-16.

56. Nilsson B, Korsgren 0, Lambris J, et al. Can cells and biomaterials in therapeutic medicine be shielded off from innate immune recognition? Trends Immunol 2010;31:32.

57. Smith JG, Smith AJ, Shelton RM, et al. Recruitment of dental pulp cells by dentine and pulp extracellular matrix components. Exp Cell Res 2012;318:2397-406.

58. Wang MC, Hung PS, Tu HF, et al. Lipopolysaccharide induces the migration of human dental pulp cells by up-regulating miR-146a. J Endod 2012;38:1598-603.

59. Suzuki T, Lee $\mathrm{CH}$, Chen M, et al. Induced migration of dental pulp stem cells for in vivo pulp regeneration. J Dent Res 2011;90:1013-8.

60. Jiang L, Peng WW, Li LF, et al. Isolation and identification of CXCR4-positive cells from human dental pulp cells. J Endod 2012;38:791-5.

61. Jiang L, Peng WW, Li LF, et al. Proliferation and multilineage potential of CXCR4positive human dental pulp cells in vitro. J Endod 2012;38:642-7. 